\title{
Iridoid and Phenylethanoid Glycosides from Phlomis tuberosa $\mathbf{L}$.
}

Tayfun Ersöz ${ }^{\mathrm{a}, *}$, Stefanka Ivancheva ${ }^{\mathrm{b}}$, Pınar Akbayc, Otto Sticher ${ }^{\mathrm{c}}$ and

İhsan Çalış ${ }^{\mathrm{a}}$

a Department of Pharmacognosy, Faculty of Pharmacy, Hacettepe University TR-06100, Ankara, Turkey.

Fax: +90-312-3114777. E-mail: tersoz@hacettepe.edu.tr

b Institute of Botany, Bulgarian Academy of Sciences, Sofia 1113, Bulgaria

c Department of Applied BioSciences, Institute of Pharmaceutical Sciences, ETH-Zurich, Winterthurerstr. 190, CH-8057 Zürich, Switzerland

* Author for correspondence and reprint requests

Z. Naturforsch. 56c, 695-698 (2001); received April 17/May 22, 2001

Phlomis, Iridoid Glucosides, Phenylethanoid Glycosides

A new iridoid glucoside, 8-O-acetylshanzhiside (1), was isolated from the aerial parts of Phlomis tuberosa, together with two known iridoid glucosides, shanzhiside methyl ester and lamalbide. The known phenylethanoid glycosides acteoside and forsythoside B were also obtained and characterized. The structure of 1 was determined by means of $1 \mathrm{D}$ - and 2DNMR spectroscopic evidence.

\section{Introduction}

Phlomis tuberosa L. (Lamiaceae) is a widespread plant in Bulgaria (Stojanov et al., 1967). There exist several reports on the flavonoids and polyphenolic compounds (Gella et al., 1972; Glyzin et al., 1972; Vavilova and Gella, 1973a and 1973b) and alkaloids (Khokhrina and Peshkova, 1974) from this plant. However, $C_{9}$ iridoids, harpagide and 8-O-acetyl harpagide have been described from P. tuberosa (Gella and Vavilova, 1972) but a recent study on the same plant species led to the isolation of 5-desoxysesamoside, sesamoside, shanzhiside methyl ester and lamalbide, all $\mathrm{C}_{10}$ iridoid glucosides with a C-4 methoxycarbonyl substituent (Alipieva et al., 2000). The present study on $P$. tuberosa, has now resulted in the isolation of a new iridoid glucoside, 8- $O$-acetylshanzhiside (1), in addition to the known iridoid glucosides shanzhiside methyl ester (2) and lamalbide (3) as well as the known phenylethanoid glycosides acteoside (4) and forsythoside B (5). This paper deals with the structure elucidation of $\mathbf{1}$ by 1D- and 2D-NMR spectroscopy.

\section{Material and Methods}

\section{General experimental procedures}

Optical rotation was measured on a Perkin-Elmer 241\&241 MC polarimeter using $\mathrm{MeOH}$. UV spectra were recorded on a UVIKON 930 spectro- photometer in $\mathrm{MeOH}$. FTIR spectra were recorded on a Perkin-Elmer 2000 FT-IR spectrometer in $\mathrm{KBr}$ pellets. NMR measurements in $\mathrm{CD}_{3} \mathrm{OD}$ at room temperature were performed on a Bruker DRX 500 spectrometer operating at 500 and 125 $\mathrm{MHz}$ for ${ }^{1} \mathrm{H}$ and ${ }^{13} \mathrm{C}$ NMR, respectively. ${ }^{1} \mathrm{H}-{ }^{1} \mathrm{H}$ COSY, ${ }^{1} \mathrm{H}_{-}{ }^{13} \mathrm{C}$ HSQC, and ${ }^{1} \mathrm{H}_{-}{ }^{13} \mathrm{C}$ HMBC experiments were recorded by employing conventional pulse sequences. ESIMS were recorded in positive and negative ion modes on a Finnigan TSQ 7000 mass spectrometer. LiChroprep $\mathrm{C}_{18}$ (Merck) was used for VLC (column $5.2 \times 20 \mathrm{~cm}$, i.d.). Silica gel $60(0.063-0.200 \mathrm{~mm}$, Merck) was used for open column CC. MPLC (medium pressure liquid chromatography) separations were performed on a Labomatic glass column $(1.8 \times 35.2 \mathrm{~cm}$, i.d. $)$ packed with LiChroprep $\mathrm{C}_{18}$ (Merck), using a Lewa M5 peristaltic pump. TLC was carried out on precoated silica gel $60 \mathrm{~F}_{254}$ aluminum sheets (Merck). Compounds were detected by UV fluorescence absorption and/or spraying with vanillin- $\mathrm{H}_{2} \mathrm{SO}_{4}$ reagent followed by heating at $100{ }^{\circ} \mathrm{C}$ for $1-2 \mathrm{~min}$.

\section{Plant material}

Phlomis tuberosa (Lamiaceae) was collected at florescence in West Stara Planina (West Balkan), Bulgaria in May 1998. A voucher specimen has been deposited in the herbarium of the Institute of Botany, Bulgarian Academy of Sciences [SOM 154959]. 


\section{Extraction and isolation}

The air-dried and powdered aerial parts of $P$. tuberosa $(86 \mathrm{~g})$ were extracted twice with $\mathrm{MeOH}$ $(2 \times 500 \mathrm{ml})$ at $40^{\circ} \mathrm{C}$. The combined extracts were evaporated under reduced pressure and $\mathrm{H}_{2} \mathrm{O}$ was added $(500 \mathrm{ml})$. The $\mathrm{H}_{2} \mathrm{O}$-insoluble material was removed by filtration and the filtrate then partitioned with $\mathrm{CHCl}_{3}$. The $\mathrm{CHCl}_{3}$ layer was removed. The aqueous layer was concentrated under reduced pressure to yield $6.59 \mathrm{~g}$ crude extract. The crude extract was then fractionated by reversedphase vacuum liquid chromatography (RP-VLC, LiChroprep $\mathrm{C}_{18}$ ) and eluted with $\mathrm{H}_{2} \mathrm{O}$, followed by increasing concentrations of $\mathrm{MeOH}(5-100 \%)$ to yield 6 main fractions (A-F) [Fr. A (2.282 g), Fr. B (65 mg), Fr. C (133.7 mg), Fr. D (114.6 mg), Fr. E (245 mg), Fr. F (314.4 mg)]. Fraction C was subjected to $\mathrm{C}_{18}$ medium pressure liquid chromatography (RP-MPLC) using gradient $\mathrm{MeOH}-\mathrm{H}_{2} \mathrm{O}$ $(5-30 \%)$ mixtures to yield shanzhiside methyl ester (2) (4.85 mg) and lamalbide (3) (13.4 mg). CC of fraction $\mathrm{D}$ on silica gel $(15 \mathrm{~g})$ eluting with $\mathrm{CHCl}_{3}-\mathrm{MeOH}-\mathrm{H}_{2} \mathrm{O}$ (80:20:1, 80:20:2) mixtures afforded 6 fractions (Frs. $\left.\mathrm{D}_{1}-\mathrm{D}_{6}\right)$. Fraction $\mathrm{D}_{5}(9 \mathrm{mg})$ was purified by Sephadex $\mathrm{CC}$ with $\mathrm{MeOH}$ to give $1(3.0 \mathrm{mg})$. Fraction E was applied to RP-MPLC and fractionated with isopropanol- $\mathrm{H}_{2} \mathrm{O}(5-20 \%)$ mixtures to yield acteoside (4) $(37.7 \mathrm{mg})$ and forsythoside B (5) (115 mg).

8-O-acetylshanzhiside (1), white amorphous powder, $3.0 \mathrm{mg}$. $[\alpha]_{\mathrm{D}}{ }^{20}-42^{\circ}(c 0.1, \mathrm{MeOH})$; UV $(\mathrm{MeOH}) \lambda_{\max }(\log \varepsilon) 205$ (2.88); IR $v_{\max }(\mathrm{KBr})$ $\mathrm{cm}^{-1}: 3450(\mathrm{OH}), 1739$ (ester), $1695 \quad(\mathrm{C}=\mathrm{C}-$ $\mathrm{COOH}), 1400\left(\mathrm{CH}_{3}\right), 1250$ (=C-O-C), $1100(\mathrm{CH}-$ $\mathrm{OH})$. Positive-ion ESIMS: $m / z[\mathrm{M}+\mathrm{Na}]^{+} 457$ (93); negative-ion ESIMS: $m / z[\mathrm{M}-\mathrm{H}]^{-} 433(100) .{ }^{1} \mathrm{H}$ NMR $\left(\mathrm{CD}_{3} \mathrm{OD}, 500 \mathrm{MHz}\right)$ : Table I. ${ }^{13} \mathrm{C}$ NMR $\left(\mathrm{CD}_{3} \mathrm{OD}, 125 \mathrm{MHz}\right)$ : Table I.

\section{Results and Discussion}

The methanol extract of $P$. tuberosa was suspended in water and partitioned with chloroform. Removing the chloroform layer, the aqueous layer was fractionated over reversed-phase vacuum liquid chromatography (RP-VLC, LiChroprep $\mathrm{C}_{18}$ ) followed by $\mathrm{Si}$ gel $\mathrm{CC}$ and $\mathrm{C}_{18}$ medium pressure liquid chromatography (RP-MPLC) and purification over Sephadex yielded pure compounds 1-5.

The known compounds $\mathbf{2 - 5}$ were identified as shanzhiside methyl ester (2) (Achenbach et al., 1981), lamalbide (3) (Brieskorn and Ahlborn, 1973; Ersöz et al., 2001), acteoside (4) (Sticher and Lahloub, 1982), and forsythoside B (5) (Endo et al., 1982), respectively, by comparing their ${ }^{1} \mathrm{H}$ and ${ }^{13} \mathrm{C}$ NMR data with previously published data.

Compound 1 was isolated as an amorphous powder, $[\alpha]_{\mathrm{D}}^{20}-42^{\circ}(c 0.1, \mathrm{MeOH})$. The molecular formula was established as $\mathrm{C}_{18} \mathrm{H}_{26} \mathrm{O}_{12}$, on the basis of the ${ }^{1} \mathrm{H}$ and ${ }^{13} \mathrm{C}$ NMR data (see Table I), and of the pseudomolecular ions shown in positive ESI-MS $\left(\mathrm{m} / z 457[\mathrm{M}+\mathrm{Na}]^{+}\right)$and negative ESI-MS $\left(\mathrm{m} / z 433[\mathrm{M}-\mathrm{H}]^{-}\right)$. The ${ }^{1} \mathrm{H}$ NMR spectrum of $\mathbf{1}$ exhibited signals for a conjugated iridoid structure with an acetoxy $\left(\delta_{\mathrm{H}} 2.00, s\right)$ and a tertiary methyl

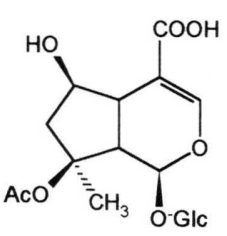

1

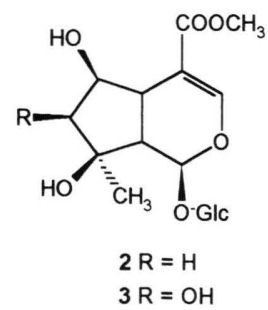

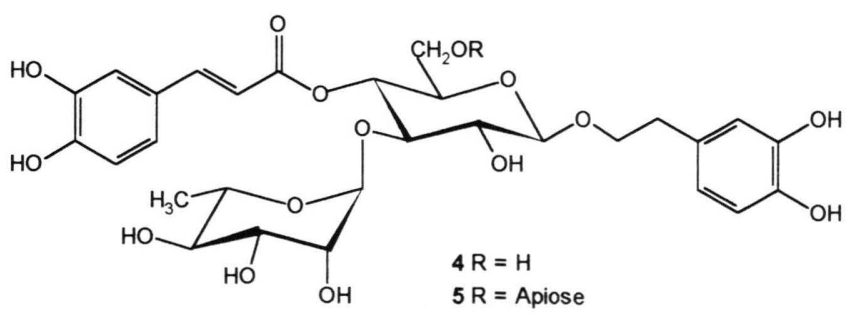


Table I. ${ }^{13} \mathrm{C}$ and ${ }^{1} \mathrm{H}$ NMR $\left(\mathrm{CD}_{3} \mathrm{OD}, 125 \mathrm{MHz}\right.$ for ${ }^{13} \mathrm{C}$ and $500 \mathrm{MHz}$ for ${ }^{1} \mathrm{H}$ NMR) data and $\mathrm{HMBC}$ correlations for $\mathbf{1}^{*}$.

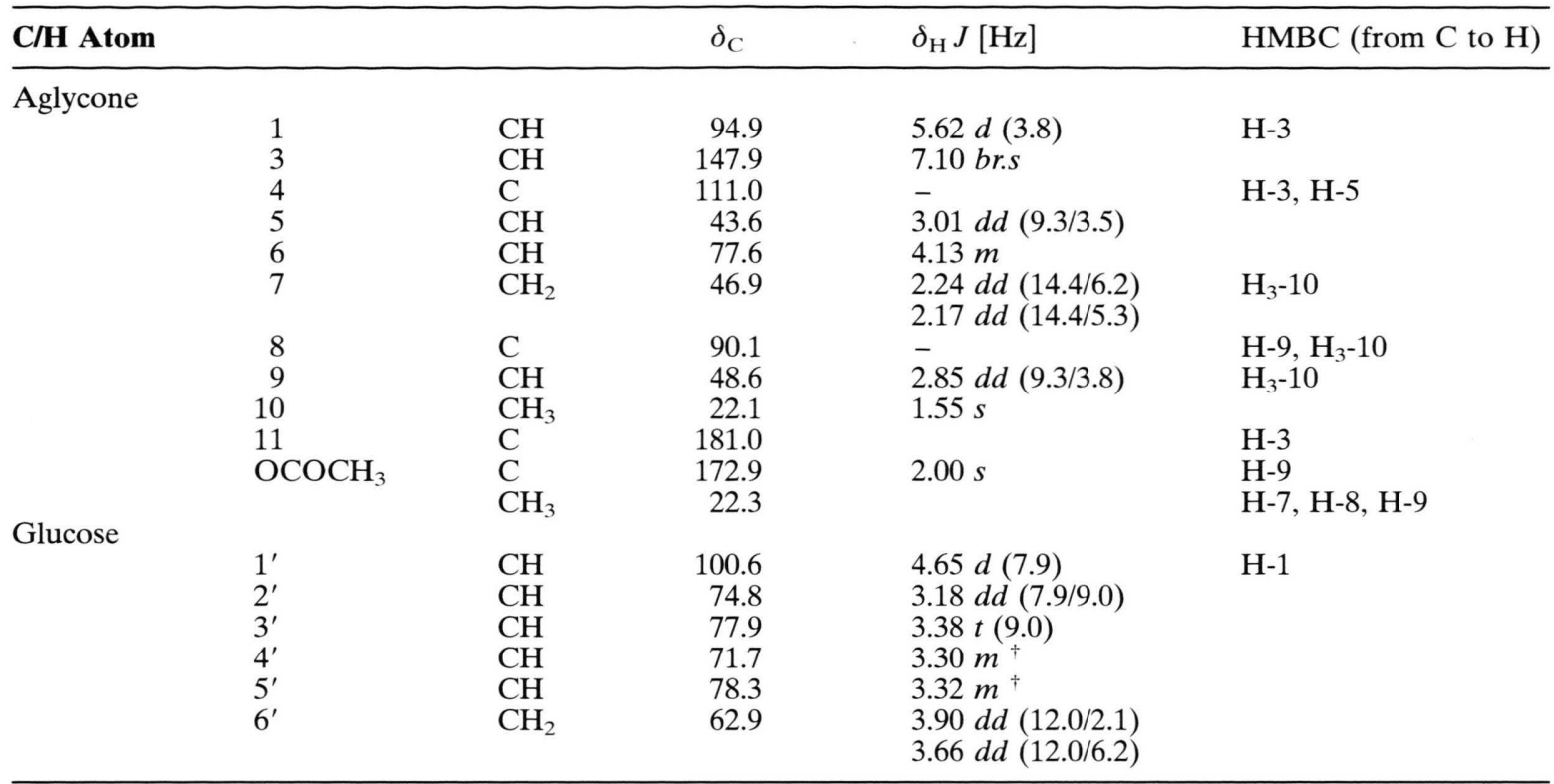

*The ${ }^{13} \mathrm{C}$ and ${ }^{1} \mathrm{H}$ NMR assignments were based on HSQC, HMBC and COSY experiments.

${ }^{\dagger}$ Coinciding with the solvent signal or pattern and therefore unclear due to signal overlapping.

$\left(\delta_{\mathrm{H}} 1.55, s\right)$ function. In addition, the ${ }^{1} \mathrm{H}$ NMR signal at $\delta_{\mathrm{H}} 4.65(d, J=7.9 \mathrm{~Hz})$ was attributed to the anomeric proton signal of a $\beta$-glucose unit. In the ${ }^{13} \mathrm{C}$ NMR spectrum 18 carbon resonances, six of which could be assigned to a $\beta$-glucopyranosyl moiety, were observed. The complete assignments of all proton and carbon resonances were made by ${ }^{1} \mathrm{H}-{ }^{1} \mathrm{H}$ COSY, ${ }^{1} \mathrm{H}_{-}{ }^{13} \mathrm{C}$ HSQC and HMBC experiments. Therefore, HMBC correlation observed between $\mathrm{C}-1$ ' $\left(\delta_{\mathrm{C}} 100.6, d\right)$ and $\mathrm{H}-1$ revealed the attachment of the $\beta$-glucopyranose unit at the $\mathrm{C}$ - 1 position of the iridoid aglycone. The ${ }^{1} \mathrm{H}$ NMR signal at $\delta_{\mathrm{H}} 7.10$ (br.s) was assigned to $\mathrm{H}-3$, suggesting $\mathrm{H}-4$ to be substituted, which was further verified by the typical ${ }^{13} \mathrm{C} \mathrm{NMR}$ resonances associated with a $\mathrm{C}-4$ carboxy-bearing iridoid in the region C-3 to C-5 $\left(\delta_{\mathrm{C}}[\mathrm{C}-3] 147.9, d ; \delta_{\mathrm{C}}[\mathrm{C}-4] 111.0, s ; \delta_{\mathrm{C}}\right.$ [C-5] 43.6, $d)$, as well as by the HMBC correlation from $\mathbf{C O O H}\left(\delta_{\mathrm{C}} 181.0, s\right)$ to $\mathrm{H}-3$. In the ${ }^{1} \mathrm{H}-{ }^{1} \mathrm{H}$ COSY spectrum, $\mathrm{H}-1$ signal $\left(\delta_{\mathrm{H}} 5.62, d, J=3.8\right.$ $\mathrm{Hz})$ was coupled to $\mathrm{H}-9\left(\delta_{\mathrm{H}} 2.85, d d, J=9.3 / 3.8\right.$ $\mathrm{Hz})$, which in turn was correlated to $\mathrm{H}-5\left(\delta_{\mathrm{H}} 3.01\right.$, $d d, J=9.3 / 3.5 \mathrm{~Hz}$ ), indicating C-5 to be unsubstituted. $\mathrm{H}-5$ exhibited a ${ }^{1} \mathrm{H}-{ }^{1} \mathrm{H}$ COSY interaction with an oxymethine proton at $\delta_{\mathrm{H}} 4.13(m, \mathrm{H}-6)$, consistent with the hydroxyl group being attached to $\mathrm{C}-6\left(\delta_{\mathrm{C}} 77.6, d\right)$. The secondary hydroxyl function at $\mathrm{C}-6$ was assigned as $\beta$ by comparing the ${ }^{13} \mathrm{C}$ NMR data of 1 with those of C-6 $(\mathrm{OH})$ epimer iridoid glucosides (Bianco et al., 1983). In the ${ }^{1} \mathrm{H}-$ ${ }^{1} \mathrm{H}$ COSY spectrum, H-6 proton showed an additional homonuclear coupling with the geminally coupled C-7 methylene protons $\left(\delta_{\mathrm{H}} 2.24, d d, J=\right.$ $14.4 / 6.2 \mathrm{~Hz}, \mathrm{H}-7 \alpha ; \delta_{\mathrm{H}} 2.17, d d, J=14.4 / 5.3 \mathrm{~Hz}, \mathrm{H}-$ $7_{\beta}$; observed as $\mathrm{AB}$ part of an $\mathrm{ABX}$ system). HMBC correlation observed from C-8 $\left(\delta_{\mathrm{C}} 90.1, s\right)$ to the tertiary methyl signal $\left(\delta_{\mathrm{H}} 1.55, s\right)$, in addition to the heteronuclear long-range couplings between $\mathrm{H}_{3}-10 / \mathrm{C}-7\left(\delta_{\mathrm{C}} 46.9, t\right)$ and $\mathrm{H}_{3}-10 / \mathrm{C}-9\left(\delta_{\mathrm{C}}\right.$ $48.6, d)$, showed the attachment of the methyl group at $\mathrm{C}-8$. On the other hand, the chemical shift values of both $\mathrm{C}-8$ and $\mathrm{H}_{3}-10$ indicated an oxygen substitution at C-8 position. However, C8 resonance showed a remarkable downfield shift compared with the iridoid analogues with a tertiary methyl and a hydroxyl group bearing at C-8 (Boros and Stermitz, 1990). Therefore, the acetoxy function in $\mathbf{1}$ was assigned to be positioned at the tertiary hydroxyl group at C-8 causing downfield shifts of both $\mathrm{H}_{2}-7\left(\delta_{\mathrm{H}} 2.24, d d J=14.4 / 6.2 \mathrm{~Hz}\right.$ and 
2.17, $d d J=14.4 / 5.3 \mathrm{~Hz})$ and $\mathrm{H}-9\left(\delta_{\mathrm{H}} 2.85, d d J=\right.$ 9.3/3.8 Hz). Moreover, a significant HMBC crosspeak from $\mathrm{OCOCH}_{3}\left(\delta_{\mathrm{C}} 172.9, s\right)$ to H-9 also supported this assumption. The complete NMR data of 1 based on ${ }^{1} \mathrm{H}_{-}{ }^{1} \mathrm{H}$ and ${ }^{1} \mathrm{H}_{-}{ }^{13} \mathrm{C}$ 2D-NMR measurements indicated that the structure of $\mathbf{1}$ was almost identical to that of 8 - $O$-acetylshanzhiside methyl ester (Damtoft et al., 1982; Nicoletti et al., 1984), except for the substitution of a carboxyl group at C-4. Consequently, compound $\mathbf{1}$ was established as $8-O$-acetylshanzhiside which was isolated for the first time from nature.

Concerning the iridoid glucosides of the genus Phlomis, only $\mathrm{C}_{10}$ iridoids, substituted with a methoxycarbonyl function at $\mathrm{C}-4$ have been described up to now. To our knowledge, 8 - $O$-acetylshanzhiside (1) is the first iridoid glucoside substituted at $\mathrm{C}-4$ by a $\mathrm{COOH}$ group- reported from Phlomis species, which may be of chemotaxonomic importance in the future. On the other

Achenbach H., Waibel R., Raffelsberger B. and AddaeMensah I. (1981), Iridoid and other constituents of Canthium subcordatum. Phytochemistry 20,1591-1595.

Alipieva K. Iv., Jensen S. R., Franzyk H., Handjieva N. V. and Evstatieva, L. N. (2000), Iridoid glucosides from Phlomis tuberosa L. and Phlomis herba-ventis L. Z. Naturforsch. 55c, 137-140.

Bianco A., Passacantilli P., Polidori G., Nicoletti M. and Messana I. (1983), NMR spectroscopy of epimeric pairs of glucosidic iridoids. Gazz. Chim. Ital. 113, 829-834.

Boros C. A. and Stermitz F. R. (1990), Iridoids. An updated review. Part I. J. Nat. Prod. 53, 1055-1147.

Brieskorn C. H. and Ahlborn R. (1973), Ein neues iridoid aus flores Lamii albi. Tetrahedron Lett. 41 , 4037-4038.

Damtoft S., Jensen S. R. and Nielsen B. J. (1982), Structural revision of barlerin and acetyl barlerin. Tetrahedron Lett. 23, 4155-4156.

Endo K., Takahashi K., Abe T. and Hikino H. (1982), Structure of forsythoside B, an antibacterial principle of Forsythia coreana stems. Heterocycles 19, 261-264

Ersöz T., Schühly W., Popov S., Handjieva N., Sticher O. and Çalış İ. (2001), Iridoid and phenylethanoid glycosides from Phlomis longifolia var. longifolia, Nat Prod. Lett. (in press).

Gella E. V., Vavilova N. K. and Litvinenko, V. I. (1972), Polyphenolic compounds from Phlomis tuberosa. Rast. Resur. 8, 554-556 (Russ.). hand, iridoid composition of P. tuberosa, collected from West Stara Planina-West Balkan region was somewhat different from that of $P$. tuberosa collected from Barmuk bair-Sliven region (Alipieva et al., 2000). This could illustrate a significant geographic variation of the iridoids in the same species.

Although Phlomis species are known to contain phenylethanoid glycosides (Jimenez and Riguera, 1994), no phenylethanoid glycoside has so far been reported from P. tuberosa. Therefore, acteoside (4) and forsythoside B (5) are the first phenylethanoid glycosides isolated from the title plant.

\section{Acknowledgements}

The authors are thankful to Dr. Oliver Zerbe (ETHZ) for the NMR measurements and to Dr. Engelbert Zass for his help in literature search. Special thanks to Oswald Greter and Dr. Walter Amrein (ETHZ) for recording the mass spectra.

Glyzin V. I., Peshkova V. A. and Khokhrina T. A. (1972), Luteolin 7 $\beta$-D-glucoronide from Phlomis tuberosa. Chim. Prirod. Soedin. 8, 802-803 (Russ.).

Jimenez C and Riguera R. (1994), Phenylethanoid glycosides in plants: Structure and biological activity. Nat. Prod. Rep. 11 (6), 591-606.

Khokhrina T. A. and Peshkova V. A. (1974), Stachydrine from Phlomis tuberosa and Danzeria lanata. Chim. Prirod. Soedin. 10, 265 (Russ.).

Nicoletti M., Chapya W. A., Messana I., Galeffi C., Sperandei M. and Marini-Bettolo G. B. (1984), Research on African medicinal plants. VII. New iridoid glucosides from two Rubiaceae: Mussendia arcuata Lam. and Tarenna graveolens (S. Moore) Bremek. Gazz. Chim. Ital. 114, 49-53.

Sticher O. and Lahloub M. F. (1982), Phenolic glycosides of Paulownia tomentosa. Planta Med. 46, 145-148.

Stojanov N., Stephanov B. and Kitanov B. (1967), in: Flora Bulgarica. Nauka i Iskustvo, Sofia, p 904-905 (Bul.).

Vavilova N. K. and Gella E. V. (1973a), Flavonoids from Phlomis tuberosa. Chim. Prirod. Soedin. 9, 151-153 (Russ.).

Vavilova N. K. and Gella E. V. (1973b), Homoorientin from Phlomis tuberosa. Chim. Prirod. Soedin. 9, 285286 (Russ.). 